\title{
The Involvement Level of Extension Agent in Activities Based on Rice Check Technology at IADA PEKAN Pahang, Malaysia
}

\author{
Munifah Siti Amira Yusuf ${ }^{1}$, Salim Hassan ${ }^{1}$, Olagunju Oluwatoyin ${ }^{1,2}$, \\ Nor Latifah Mohd Hanif ${ }^{1}$
}

\author{
${ }^{I}$ Department, of Agriculture Technology, Faculty of Agriculture, University Putra Malaysia, Malaysia \\ ${ }^{2}$ Department of Agricultural Economics and Extension, Faculty of Agriculture, Adekunle Ajasin \\ University, Nigeria
}

\begin{abstract}
Rice is a staple food for Malaysian and productivity must be focus upon in order to meet the increasing demand as the country growing population increases. Government had to produce a new and good variety of paddy which is MR219 and also to provide the Technology of Rice check as a manual and guideline to the extension agents to meet the needs of the farmers. However, the current yield at IADA Pekan is only 2.6 $\mathrm{mt} / \mathrm{ha}$ which is not even up to the half of the potential yield of $10 \mathrm{mt} / \mathrm{ha}$. Therefore, this study aimed to measure the involvement level and work performance of extension agents in objective setting, planning, implementing, and monitoring activities in transfer of technology based on Rice Check in IADA Pekan. The study was conducted in Pekan, Pahang and 137 respondents were considered for the 3 schemes which are Pahang Tua, Ganchong and Pulau Jawa. Questionnaire was used to elicit response from the respondents and the data was analyzed using SPSS. Based on the result obtained, the respondents at IADA Pekan has moderate level of practice toward rice check technology and the relationship between management function and work performance is also moderate.
\end{abstract}

Keywords: extension agent, planning, implementing, monitoring, rice technology

\section{INTRODUCTION}

Agriculture is one of the important sectors that contribute maximally to the economic development of Malaysia and also serves as a food source to the entire worldwide including animals. The food demand of the people is increasing yearly due to growing populations. There is no technique to survive for long without food and this can create a lot of challenges to the economy of Malaysia if attention is not given this sector. Malaysian consumes rice as their main source of energy for daily living. According to [1], it was reported that paddy production has increased from year 2010 to 2014. This means that the demand has also increased in order to cater for the growth population. As a result of this, government has taken a serious action in which a total of RM6 billion were allocated to Ministry of Agriculture and Agro-Based Industry as a budget in 2015 with the formation of special agency to monitor and supervise paddy sectors in Malaysia. This idea is similar to Integrated Agriculture Development Area (IADA) and many others agency that are related directly or indirectly to Malaysian agricultural sector. All of the agencies need maximum cooperation in other to achieve this goal and optimum yield production.

The paddy industry in Malaysia was moved drastically from traditional practices to the conventional practices. Now, we are moving forward by using technologies that has been tested by the extension agents such as Rice Check and this will also be practice by the respondents. A new rice variety, MR219, has been developed by the Malaysian Agricultural Research and Development Institute (MARDI) and it was officially released in January, 2001. This was the first variety to be developed by means of a direct seedling plant system. However, the variety is considered high-yielding rice with a suitable quality in shape and taste, but it is sensitive to environmental changes. This variety is recommended to the respondents to be planted because of its good characteristics which expected MR219 variety to be capable of producing yields of more than $10 \mathrm{mt} / \mathrm{ha}$.

Government has made a decision to open IADA at Pekan to increase the respondents yield. Pekan and Rompin will be the new granary areas of the country after the recent upgraded project area under rice cultivation was carried out at these locations within the Tenth Malaysia Plan [2]. The Integrated Agricultural Development Area (IADA) will be established to coordinate all projects related to upgrading these areas (Noh Omar, 2010) [3]. The existing rice cultivation area is capable to serve as a granary, thereby increasing the country's rice 
production. In general, IADA Pekan started operation by year 2013 with a total area of paddy cultivation of 7,211 hectares. IADA Pekan consists of six schemes that have been planted by paddy. From these six schemes, it was divided to four extension area so as to monitor the activities of the respondents.

There are three activities covered in this management function of the extension agents in transfer of technology to the respondents at IADA Pekan. The three basic stages include planning, implementing and monitoring activities. Based on these three aspects in technology transfer involving the management functions of planning, implementing and monitoring, they may influence the work performance at IADA Pekan which can be an indicator in measuring the efficiency of technology transfer between extension agents and respondents. Objective setting of the extension agents is also one of the components that will affect their work performance based in the process of transferring technology according to Rice check toward the respondents at IADA Pekan. Planning activity is the platform for implementation and monitoring, implementing is a guide for the activities plan and monitoring provide the information or result based on planning and implementing. Hence, the involvement level of extension agents in IADA Pekan, Pahang should be done in order to see the relationship between those four aspects with their work performance.

Agricultural extension officers serve as intermediaries between research and respondents. They operate as facilitators and communicators by helping them in decision-making and ensuring that appropriate knowledge received is implemented to obtain the best results. Agriculture extension is an applied social science which focused on agriculture consisting of relevant contents derived from physical, biological and social sciences and in its own processes synthesized into knowledge, principles, procedures and concepts, oriented to provide out of school education largely for adults [4]. Agriculture extension involved two components which are human resource development and the transfer of technology or knowledge from agriculture research agency to the respondents [5]. The components in transfer of technology are planning, implementing and monitoring activities based on Rice Check on paddy production at IADA Pekan.

In order to accomplish the above, it is important to understand the philosophy of Agriculture Education. This deals with the foundation upon which extension activities are based. It is the propelling forces that determine why certain actions are taken; it is related to nature of human life and guides behaviour. The basic philosophy is to help respondents to help themselves in the identification and finding solution to the problems on his farm and home. In general, planning is the first and most important function of management. It is needed at every level of management. Planning is important in this study to plan the idea or the flow of paddy production from beginning until harvesting. Implementing is the process that turns strategies and plans into actions in order to accomplish strategic objectives and goals. Monitoring is important to provides the only consolidated source of information showcasing project progress and a measurable impact on expected outcomes and have been implemented effectively [6].

A study about the role of social influence and innovation characteristics in the adoption of Integrated Pest Management (IPM) practices by paddy respondents was conducted by [7] and the finding shows that productivity of paddy can be improved by increasing innovations in agricultural production in order to get a better yield. However, a study conducted by [8], [9] comparing the factors affecting the different innovation diffusion stage-adoption and implementation still limited and required for further research.

\section{METHODOLOGY}

This study was conducted in Pekan, Pahang and it uses stratified randomized method to select the respondents. The research made use of 137 respondents from the 3 schemes which are Pahang Tua, Ganchong and Pulau Jawa based on yield range of 2.1-3.1 mt/ha. The respondents were selected based on the range yield of 2.1-3.1 mt/ha calculated from the average range yield of IADA Pekan which is $2.6 \mathrm{mt} / \mathrm{ha}$. The study material used was questionnaire which was distributed to the respondents through surveying. The questionnaire was design according to the targeted objectives of the study.

The questions that were asked in the questionnaire were mostly adapted from the Rice Check and Technology of Paddy Planting published by the Department of Agriculture. The questionnaire was divided into sixsections namely Section A-F. Section (A) is about demographic information of the respondents which include; (i) respondents region, (ii) paddy yield, (iii) purpose of production, (iv) variety of paddy, (v) year of paddy planting, (vi) land cultivated, (vii) farmer age, (viii) job focus and (ix) academic qualification. Section (B) is about objective setting to measure the involvement level of extension in the programme. The type of questions asked in this section uses Likert-scale analysis and consist of five constructs to measure the involvement of extension agent in objective setting. Section (C) is about the planning stage during the technology transfer and consists of six constructs to measure the involvement level of extension agent in planning with the use of Likert-scale as well. Section (D) is about the implementation stage during the technology transfer from the extension agents to the respondents, it consists of six constructs that measure the involvement level of extension agents during implementation. Section (E) asked seven questions about the monitoring stage during technology transfer on the level of involvement of extension agent with the use of 
Likert-scale. In Section (F), six questions were asked on the work performance of the extension agents in delivering technology to the respondents with the aid of Likert-scale. The data collected were analyzed using Statistical Package for the Social Sciences (SPSS) version 21.0.

\section{RESULT AND DISCUSSION}

In this study, the statistical procedure used to analyze the data was descriptive analysis. This analysis was done to see the involvement level of IADA Pekan extension agents in planning, implementing and monitoring. There were four components in involvement level of extension agents at IADA Pekan in transfer technology (Rice Check) for paddy crop which are objective setting, planning, implementing, and monitoring.

\section{Objective Setting}

Table 1a shows involvement level of extension agent in objective setting based on farmer's perception. Majority of the extension agents in IADA Pekan, Pahang are in the moderate level of involvement in objective setting. It consists of 67 out of 137 respondents which are $48.9 \%$ and they are at moderate level (2.68-4.34). Another $44.5 \%$ of the respondents are in the high level (4.35-6.00) with only 61 extension agents in the low level (1.00-2.67) which comprises $6.6 \%$ for 9 respondents. The mean score of objective setting, was $(M=4.17)$ which is in moderate level.

Table 1a: Involvement Level in Objective Setting

\begin{tabular}{|c|c|c|l|l|}
\hline \multicolumn{1}{|c|}{ Level } & Frequency & Percentage $(\%)$ & Mean & SD \\
\cline { 1 - 3 } Low $(1.00-2.67)$ & 9 & 6.6 & 4.17 & \multirow{2}{*}{0.93} \\
\cline { 1 - 3 } Moderate $(2.68-4.34)$ & 67 & 48.9 & & \\
\cline { 1 - 3 } High $(4.35-6.00)$ & 61 & 44.5 & & \\
\cline { 1 - 3 } Total & 137 & 100 & & \\
\hline
\end{tabular}

\section{Planning}

Table1b shows the level of involvement of extension agent in the planning stage of technology transfer based on the farmer's perception. Majority of the extension agents in IADA Pekan, Pahang are in the moderate level of involvement in planning. There are 71 respondents with 51.8\% at moderate level (2.68-4.34). Another $38.7 \%$ of the 53 respondents are in the high level (4.35-6.00), while in the low level (1.00-2.67) showed $9.5 \%$ of 13 respondents. The mean score for planning $(M=4.10)$ and is considered as moderate level.

Table 1b: Involvement Level in Planning

\begin{tabular}{|c|c|c|c|l|}
\hline \multicolumn{1}{|c|}{ Level } & Frequency & Percentage (\%) & Mean & SD \\
\cline { 1 - 4 } Low $(1.00-2.67)$ & 13 & 9.5 & 4.10 & \multirow{2}{*}{0.96} \\
\cline { 1 - 3 } Moderate $(2.68-4.34)$ & 71 & 51.8 & & \\
\cline { 1 - 3 } High (4.35-6.00) & 53 & 38.7 & & \\
\cline { 1 - 4 } Total & 137 & 100 & & \\
\hline
\end{tabular}

\section{Implementing}

Table 1c shows the level of involvement of extension agent in the implementing stage of technology transfer based on the farmer's perception. Majority of the extension agents in IADA Pekan, Pahang are in the moderate level of involvement in implementing. 74 respondents at 54\% showed moderate level (2.68-4.34). Another $27.7 \%$ of 38 respondents showed at low level (1.00-2.67) while in the high level (4.35-6.00) which comprises $18.3 \%$ of 25 respondents. The mean score is $(\mathrm{M}=3.42)$ which indicate moderate level. 
The Involvement Level of Extension Agent in Activities Based on...

Table 1c: Involvement Level in Implementing

\begin{tabular}{|c|c|c|l|l|}
\hline \multicolumn{1}{|c|}{ Level } & Frequency & Percentage (\%) & Mean & SD \\
\cline { 1 - 4 } Low $(1.00-2.67)$ & 38 & 27.7 & 3.42 & 1.17 \\
\cline { 1 - 3 } Moderate $(2.68-4.34)$ & 74 & 54.0 & & \\
\cline { 1 - 3 } High $(4.35-6.00)$ & 25 & 18.3 & & \\
\cline { 1 - 4 } Total & 137 & 100 & & \\
\hline
\end{tabular}

\section{Monitoring}

Table 1dshows the level of involvement of extension agent in the monitoring stage of technology transfer based on the farmer's perception. Majority of the extension agents in IADA Pekan, Pahang are in the moderate level of involvement in monitoring. The result showed, $61.3 \%$ of 84 respondents were at moderate level (2.68-4.34). Another $21.2 \%$ of the respondents are in the high level (4.35-6.00) with only 29 extension agents while in the low level (1.00-2.67) which comprises $17.5 \%$ for 24 respondents. The mean score of monitoring, $(\mathrm{M}=3.57)$ which is considered moderate level.

Table 1d: Involvement Level in Monitoring

\begin{tabular}{|c|c|c|c|l|}
\hline \multicolumn{1}{|c|}{ Level } & Frequency & Percentage (\%) & Mean & SD \\
\cline { 1 - 4 } Low $(1.00-2.67)$ & 24 & 17.5 & 3.57 & 1.04 \\
\cline { 1 - 3 } Moderate $(2.68-4.34)$ & 84 & 61.3 & & \\
\cline { 1 - 4 } High $(4.35-6.00)$ & 29 & 21.2 & & \\
\cline { 1 - 4 } Total & 137 & 100 & & \\
\hline
\end{tabular}

\section{Work Performance}

Table 2a shows the level of work performance of extension agent in technology transfer based on the farmer's perception. Majority of the extension agents in IADA Pekan, Pahang are in the moderate level of work performance. It consists of 75 of 137 respondents with $54.7 \%$ at moderate level. Another $35.8 \%$ of the respondents are in the high level with only 49 extension agents while in the low level which comprises $9.5 \%$ for 13 respondents. The mean mean score of performance is $(M=4.05)$ which is moderate level.

Table 2a: Work Performance Level

\begin{tabular}{|c|c|c|c|c|}
\hline Level & Frequency & Percent & Mean & Std. Deviation \\
\cline { 1 - 3 } Low $(1.00-2.67)$ & 13 & 9.5 & 4.05 & 0.95 \\
\cline { 1 - 3 } Moderate $(2.68-4.34)$ & 75 & 54.7 & & \\
\cline { 1 - 3 } High (4.35-6.00) & 49 & 35.8 & & \\
\hline Total & 137 & 100 & & \\
\hline
\end{tabular}

Summary of Mean, Standard Deviation, Level and Rank between Independent Variable and Dependent Variable

Table $2 \mathrm{~b}$ below shows the mean, standard deviation, level and rank between the independent variable and dependent variable. The highest mean between independent variables is objective setting $(\mathrm{M}=4.17)$ and 
( $\mathrm{SD}=0.93)$ respectively. Followed by planning $(\mathrm{M}=4.10)$ and $(\mathrm{SD}=0.96)$. The mean score for monitoring is $(\mathrm{M}=3.57)$ and $(\mathrm{SD}=1.04)$. The least one is implementing which represented $(\mathrm{M}=3.42)$ with $(\mathrm{SD}=1.17)$.

Table 2b: Summary of Mean, Standard Deviation, Level and Rank

\begin{tabular}{|c|c|c|c|c|}
\hline & Mean & $\begin{array}{c}\text { Standard } \\
\text { Deviation }\end{array}$ & Level \\
\hline \multicolumn{5}{|c|}{ Independent Variables } \\
\hline Objective Setting & 4.17 & 0.93 & Moderate & 1 \\
\hline Planning & 4.10 & 0.96 & Moderate & 2 \\
\hline Implementing & 3.42 & 1.17 & Moderate & 4 \\
\hline Monitoring & 3.57 & 1.04 & Moderate & 3 \\
\hline \multicolumn{7}{|c|}{ Dependent Variable } \\
\hline Performance & 4.05 & 0.95 & Moderate & \\
\hline
\end{tabular}

\section{CONCLUSION}

Management functions are very important for extension agents in paddy cultivation at IADA Pekan in order to achieve the target yield production. According to reported result, objective setting, planning, implementing and monitoring activities showed moderate level. Extension agents and respondents are very close to each other and this will make work become easier. Farmers were cooperated with the IADA extension agents in order to acquire knowledge and experience in paddy cultivation. Based on this study, researcher finds that the objective setting, planning, implementing and monitoring works need to be more emphasized since all aspects have moderate relationship with work performance. As an extension agent, objective setting, monitoring is one of the basic work that an agent needs to do. Monitoring activities need to be done in order to make sure respondents follow rice check technology very well. Monitoring is very vital in transfer of technology because after as the extension agent need to monitor them often. This is to make sure that all the knowledge acquired from the extension by the respondents is put to use effectively.

\section{REFERENCES}

[1] Agrofood Statistics (2014). Ministry of Agriculture and Agro-Based Industry, Information Management and Statistics Section, Policy and Strategic Planning Division, Wisma Tani, Putrajaya, 2015.

[2] The Tenth Malaysian Plan. Economy Planning Unit. Department of Prime Minister Malaysia. Putrajaya.

[3] Noh Omar (2010). Transitioning from Agriculture to Agribusiness. Policy and Strategic Planning Division, Wisma Tani, Putrajaya, Malaysia, 2010.

[4] Leagans, J. P. (1971). "Extension Education and Modernization in Leagans and Loom's (eds.)", Behavioural Change in Agriculture - Concepts and Strategies for Influencing Transition. Cornell Univ. Press. Ithaca pp. 101-143.

[5] A. H. O. Khalil (2008). Relationships between Extension Competencies, Organisational Commitment and Job Satisfaction with Performance of Agricultural Extension Workers in Yemen. Doctoral diss., Universiti Putra Malaysia, Malaysia.

[6] Gage, Anastasia \& Melissa Dunn. (2009). "Monitoring and Evaluating Gender-Based Violence Prevention and Mitigation Programs.” U.S. Agency for International Development, Measure Evaluation, Interagency Gender Working Group, Washington DC.

[7] Feloor \& Bahaman (2011). Role of social influence and innovation characteristics in the adoption Integrated Pest Management (IPM) practice by paddy farmers in Iran.

[8] Grover, Varun, and Martin D. Goslar (1993), "The Initiation, Adoption, and Implementation of Telecommunications Technologies in U.S. Organizations", Journal of management Information Systems, 10, 141-163.

[9] Abdullah, F. A., \& Samah, B. A. (2013). Factors impinging farmers' use of agriculture technology. Asian Social Science, 9(3), $120-124$.

Munifah Siti Amira Yusuf. "The Involvement Level of Extension Agent in Activities Based on Rice Check Technology at IADA PEKAN Pahang, Malaysia ." IOSR Journal of Agriculture and Veterinary Science (IOSR-JAVS) 10.7 (2017): 81-85. 